\title{
TCPP-Isoliensinine Nanoparticles for Mild-Temperature Photothermal Therapy
}

\author{
Chenglin Zhang ${ }^{1} * *$ \\ Xinming Wang ${ }^{2, *}$ \\ Junyou Wang ${ }^{2}$ \\ Yuening Qiu (iD) ${ }^{2}$ \\ Zhiyao $\mathrm{Qi}^{2}$ \\ Dianwen Song' \\ Mingwei Wang $\mathbb{D}^{2}$ \\ 'Department of Orthopedics, Shanghai \\ General Hospital, Shanghai Jiao Tong \\ University School of Medicine, Shanghai, \\ 201620, People's Republic of China; \\ ${ }^{2}$ State Key Laboratory of Chemical \\ Engineering, School of Chemical \\ Engineering, East China University of \\ Science and Technology, Shanghai, \\ 200237, People's Republic of China \\ *These authors contributed equally to \\ this work
}

Correspondence: Mingwei Wang State Key Laboratory of Chemical Engineering, School of Chemical Engineering, East China University of Science and Technology, 130 Meilong Road, Shanghai, 200237, People's Republic of China

Email mingweiwang@ecust.edu.cn

Dianwen Song

Department of Orthopedics, Shanghai

General Hospital, Shanghai Jiao Tong

University School of Medicine, 650

Xinsongjiang Road, Shanghai, 201620,

People's Republic of China

Email dianwen.song@shgh.cn
Purpose: Photothermal therapy (PTT) is promising for the treatment of tumors due to its advantages including minimally invasive, easy implementation and selective localized treatment. However, single PTT suffers from several limitations, such as constrained light penetration and low delivery efficiency, typically leading to heterogeneous heating and incomplete elimination of cancer cells. Therefore, combination of PTT with other therapies, eg, chemotherapy is desirable in order to achieve synergistic effects in cancer treatment.

Methods: Here, we designed a new type of TCPP-Iso combined nanoparticle for synergetic therapy for breast cancer. Specifically, photothermal agent tetra(4-carboxyphenyl) porphine (TCPP) and anti-cancer drug isoliensinine (Iso) were encapsulated in PEG- $b$-PLGA polymeric nanoparticles through a precipitation process.

Results: The obtained NPs displayed well-controlled size and high stability over time. Tuning TCPP-Iso/polymer ratio, or total concentration of drug and polymers led to increased hydrodynamic radius of NPs from 65 to $108 \mathrm{~nm}$ without disturbing the narrow size distribution. Besides, the formed NPs showed a consequently cumulative release of TCPP and of Iso. The temperature elevation ability of both TCPP NPs and TCPP-Iso NPs was TCPP-concentration dependent. Solutions of TCPP NPs that contained equivalent amount of TCPP with respect to TCPP-Iso NPs, presented the same trend and exhibited non-obvious difference in temperature elevation under certain laser power. The viability of MDA-MB-231 cells treated with TCPP-Iso NPs could be inhibited effectively at a relatively mild temperature $\left(42-43^{\circ} \mathrm{C}\right)$ compared to the other groups, which may minimize heat damage to the surrounding healthy tissues.

Conclusion: The results indicate that the TCPP-Iso combined NPs showed hardly any toxicity to normal tissue cell line, but displayed an efficient synergistic effect for killing cancer cells under laser irradiation. Our study demonstrates that the successful combination of TCPP and Iso realized a synergistic therapy effect at a relatively mild temperature, and the insights obtained here shall be helpful for designing new combined PTT agents for cancer treatment.

Keywords: photothermal therapy, TCPP, isoliensinine, combined NPs, synergistic effect

\section{Introduction}

Cancer remains one of the most lethal diseases for human beings, causing high mortality worldwide every year. ${ }^{1-4}$ Many strategies have emerged for cancer treatment, and among them, photothermal therapy (PTT) has attracted great attention due to its advantages. ${ }^{5,6}$ PTT utilizes the thermal energy induced by light-to-heat conversion materials, known as photothermal transduction agents, to kill cancer cells. $^{7,8}$ The light-responsive property makes precise targeting therapy possible as the light could precisely irradiate the tumor site, leading to minimized damage to 


\section{Graphical Abstarct}

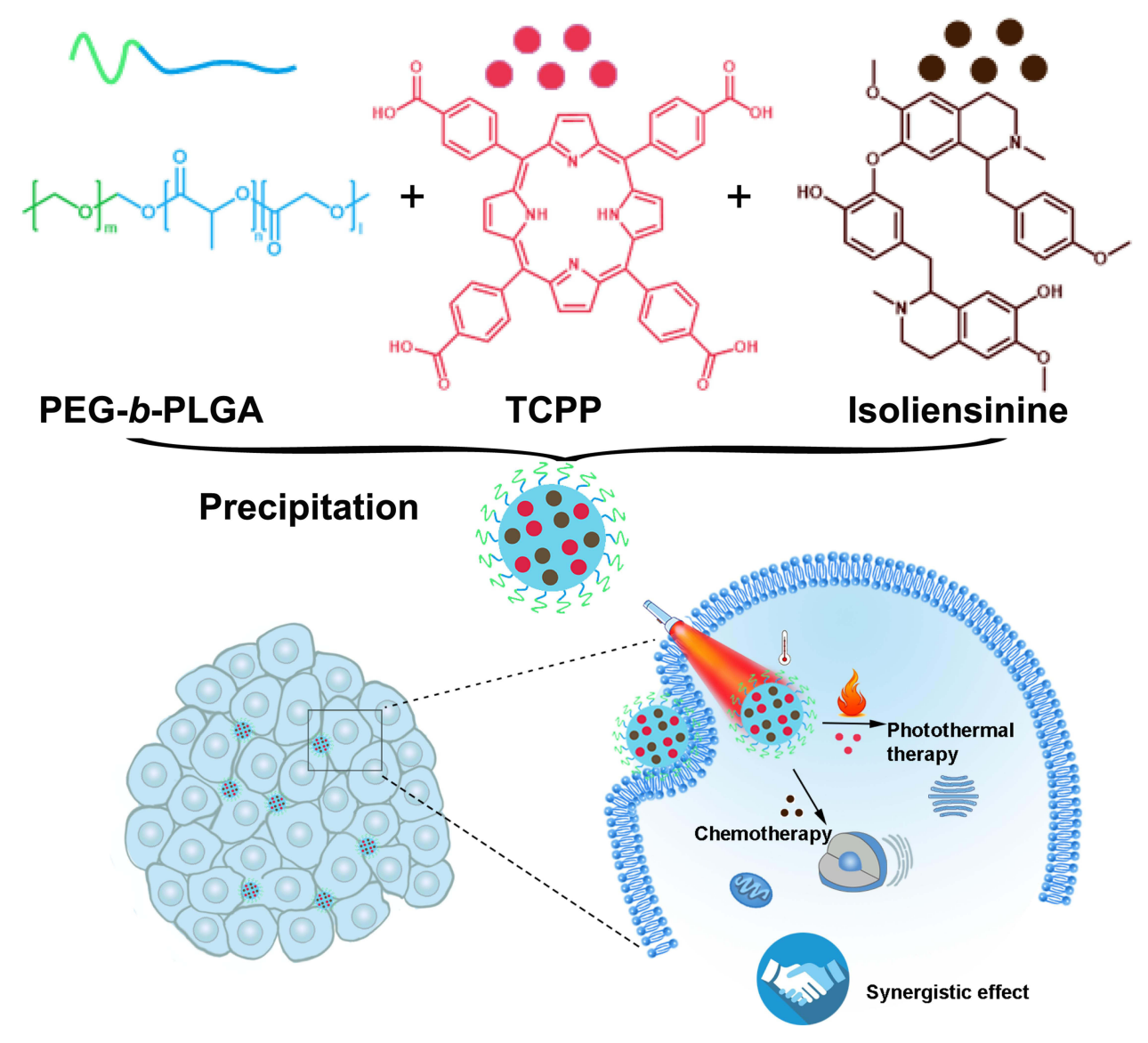

the surrounding healthy tissue. Meanwhile, PTT is a noninvasive therapy. ${ }^{9}$ Nevertheless, the PTT therapy effect is currently limited by several problems: low delivery efficiency of PTT agents in tumors, the possible development of resistance to PTT, overheating of the tumor surrounding area and uncontrolled thermal damage to surrounding normal tissues, which is from the raised concentration of PTT agent and power of irradiation light. ${ }^{10,11}$ With these limitations, single PTT typically leads to heterogeneous heating and incomplete elimination of cancer cells, and as such, combination of PTT with other therapies is desirable in order to address the challenge remaining in PTT for cancer treatment.

The combination of PTT agent with classic anti-cancer drug in a nanoscale particle is one of the promising strategies. ${ }^{12,13}$ On one hand, nanoparticle technology could offer a carrier platform for integrating multiple therapeutic functions to make best use of each agent and to obtain synergistic therapy effects. The introduction of anti-cancer drug could not only decrease the usage of PTT, leading to reduced heat in the surrounding environment and inhibiting overheating, ${ }^{14-17}$ but also improve the elimination of cancer cells as well. Meanwhile, the integration of PTT agent with anti-cancer drug could help to reduce the side effects of drug in turn by decreasing the usage of drug. ${ }^{18-22}$ On the other hand, the nanoparticle platform could also help to improve circulation and delivery efficiency accumulating in the tumor site for better treatment outcome, through the enhanced permeability and retention (EPR) effect. ${ }^{23}$ Hence, designing new combination of PTT agent and anti-cancer drug is essential for developing functional PTT agents for enhanced treatment of cancer.

Here in this work, we reported a new combination of a PTT agent with an anti-cancer drug. Specifically, tetra (4-carboxyphenyl) porphine (TCPP) was used as PTT agent, $^{24-31}$ and isoliensinine (Iso), a kind of plant-based anticancer drug, was applied as chemotherapy component. ${ }^{32-37}$ The TCPP-Iso combined nanoparticle was constructed by a precipitation method with biocompatible diblock copolymer 
PEG- $b$-PLGA as the stabilizer, as shown in Figure 1 . We investigated the effects of TCPP-Iso/polymer ratio, or total concentration of drug and polymers on the control of NP formation and sizes. The photothermal conversion and the cell apoptosis of the formed NPs were studied as well. A clear synergistic effect on killing cancer cells was revealed by the combination of TCPP and Iso, which could not be achieved by either the single PTT or chemotherapy. Our findings confirmed that TCPP-Iso is a successful combination design, and the obtained NPs displayed synergistic therapy effect, killing cancer cells at a relatively mild temperature rising. The insights obtained here shall be helpful for designing new combined PTT agents for cancer treatment.

\section{Materials and Methods}

\section{Materials}

Iso was purchased from Tomums Life Science Co., Ltd. TCPP was purchased from Tomums Life Science Co., Ltd.
PEG (5000)- $b$-PLGA (10,000) (50/50) was purchased from Shanghai Yayi Biotechnology Co., Ltd. DMF (N, N-Dimethylformamide) was purchased from Shanghai Titan Scientific Co., Ltd. Milli-Q water was used for all the solutions and experiments, obtained from purification system. Cell Counting Kit-8 (CCK-8) was bought from Beyotime Biotechnology. Calcein-AM/PI double stain kit was purchased from Yeasen Biotechnology Co., Ltd. For other chemical materials were directly used.

\section{Preparation of NPs}

The TCPP-Iso combined nanoparticles were constructed by the anti-solvent precipitation process, as shown in Figure 1. Certain amounts of TCPP, Iso, and PEG$b$-PLGA were first dissolved in $1 \mathrm{~mL} \mathrm{DMF}$, followed by stirring for half an hour at $23^{\circ} \mathrm{C} .1 \mathrm{~mL}$ of this solution was added drop-wise into $9 \mathrm{~mL}$ pure water under stirring within 1 hour. The mixed solution was stirred for an extra hour at $23^{\circ} \mathrm{C}$. The obtained nanoparticle solution

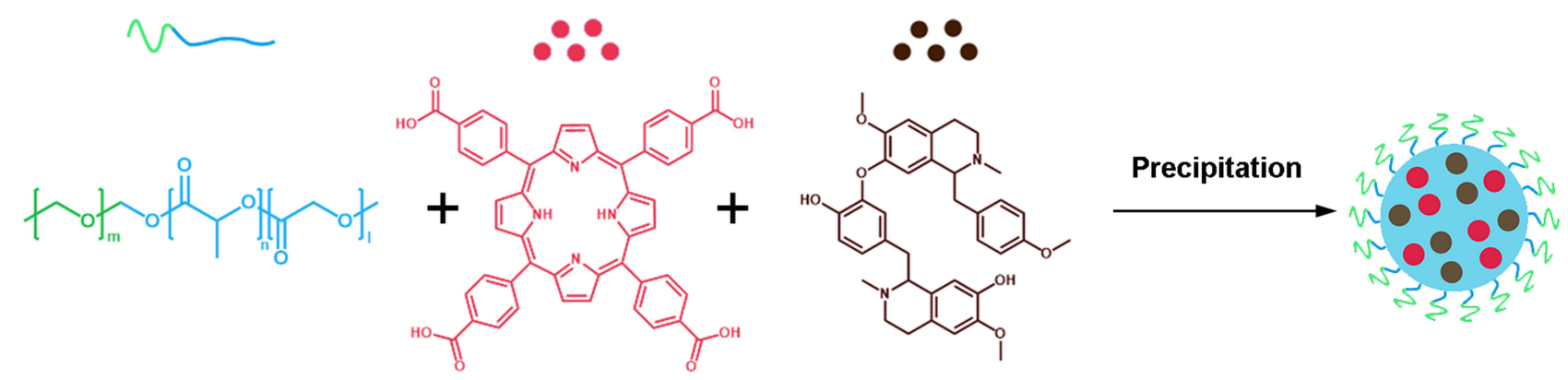

PEG-b-PLGA

TCPP

Isoliensinine

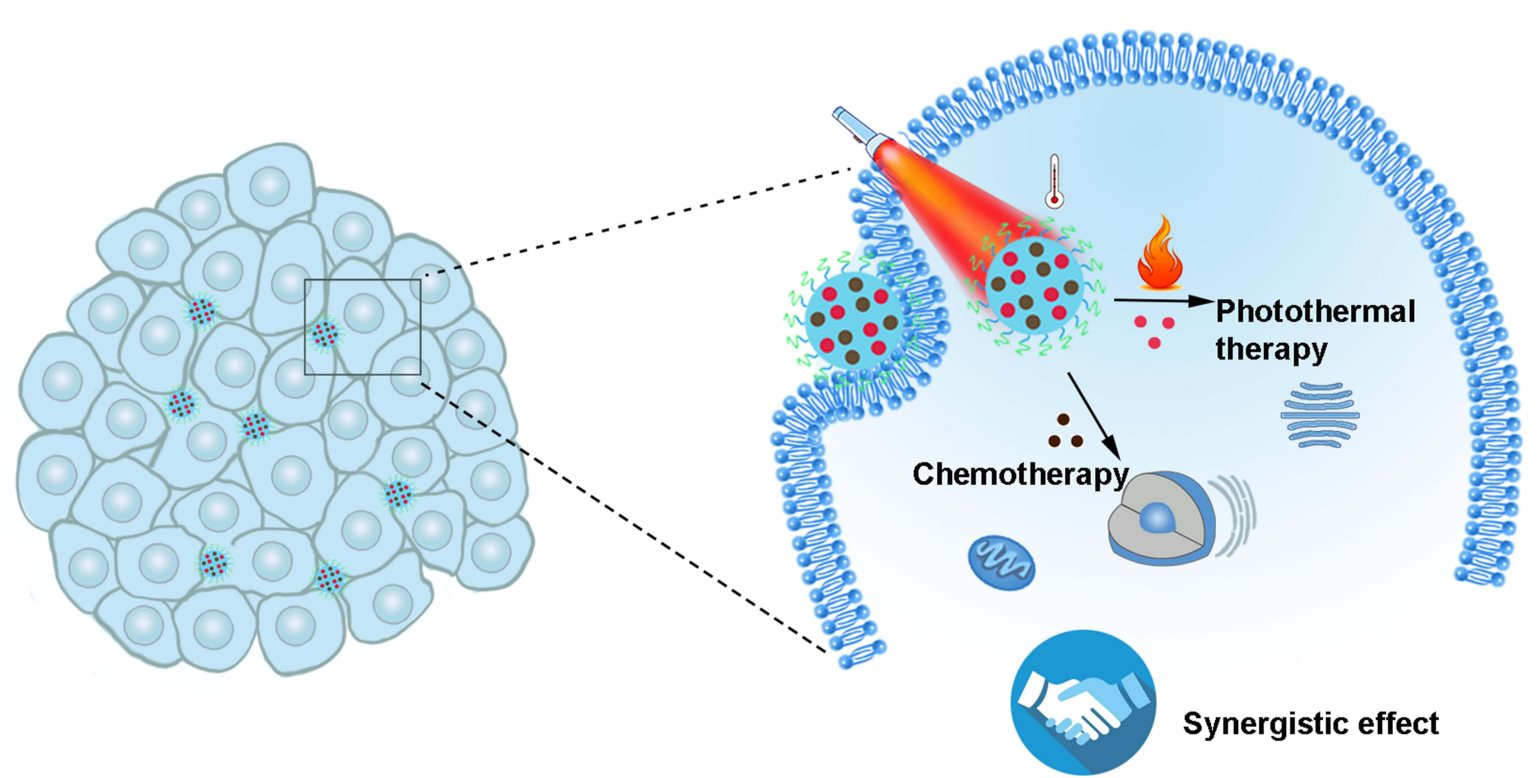

Figure I Preparation of TCPP-Iso combined NPs designed for chemo-photothermal synergistic therapy. 
was dialyzed for twenty-four hours against Milli-Q water (one-liter water per ten milliliter nanoparticle solution, 4 times) through a Spectra/Por ${ }^{\circledR} 6$ MWCO $10 \mathrm{kDa}$ dialysis membrane, to eliminate the organic solvent. The obtained nanoparticle suspension was stored at $23^{\circ} \mathrm{C}$.

\section{Characterization}

The nanoparticle sizes $\left(\mathrm{R}_{\mathrm{h}}\right.$, hydrodynamic radius) were measured by dynamic light scattering (DLS) method, which was performed in an ALV-CGS3 light scattering apparatus, at a wavelength of $632.8 \mathrm{~nm}$ and fixed angle of $90^{\circ}$, at $25^{\circ} \mathrm{C}$. The $\mathrm{Rg}$ (gyration radius) of nanoparticles was obtained from the angular dependence of scattering from $45^{\circ}$ to $120^{\circ}$ angle. The analysis of the size and distribution was CONTIN method. Six duplicates with each acquisition time of $10 \mathrm{~s}$ were performed to obtain the average and standard deviations of data. TEM (transmission electron microscopy) was observed in a JEOL JEM-1400 instrument with an acceleration voltage of $100 \mathrm{kV}$, to obtain the NP morphology. For preparation of nanoparticle sample for TEM, the nanoparticle suspensions were first diluted 2 times, and then one drop was deposited on carbon-coated copper grid. For the UV-vis absorption spectra, a UV-1800 UVvis spectrophotometer was used.

\section{Determination of the in vitro Drug Release Study}

The release rate of TCPP, Iso from NPs was investigated according to the following steps. Firstly, one milliliter drug-loaded nanoparticles were put inside dialysis membrane, which was immersed in ten milliliters PBS solution at $37^{\circ} \mathrm{C}$. At certain time intervals, one milliliter solution was retrieved from outside solution and characterized by UV-vis at $37^{\circ} \mathrm{C}$. The standard curve of TCPP was formed through UV-vis absorbance at $521 \mathrm{~nm}$ as a function of TCPP concentration, while the standard curve of Iso was obtained at $290 \mathrm{~nm}$ (Figure S1). The release UV absorbance was measured at 521 and $290 \mathrm{~nm}$ after certain amount of time using the following equation (1).

CumulativeRelease $(\%)=\frac{10 \times \mathrm{A}_{\mathrm{t}}}{\mathrm{A}_{0}} \times 100$ (1)

$A_{0}$ is the absorbance of stock solution, and $A_{t}$ is the absorbance of released drugs at time point $t$, which is obtained by measuring the absorbance of outside solution of dialysis tube.

\section{Photothermal Effect}

In a typical assay, $1 \mathrm{~mL}$ TCPP-Iso NPs and TCPP NPs in aqueous solution at different concentrations of TCPP $(0$, $10,30,50 \mu \mathrm{g} / \mathrm{mL})$ were held in a cuvette $(1 \times 1 \mathrm{~cm}$ in cross section), and were then irradiated by a $650 \mathrm{~nm}$ laser (MDL-III-650, Changchun New Industries Optoelectronics Technology Co., Ltd, China) at a power density of $6.5 \mathrm{~W} \cdot \mathrm{cm}^{-2}$ for $10 \mathrm{~min}$. The evolution of temperatures was recorded by using infrared thermal camera (Magnity Electronics, China). Then the temperature change of each aqueous solution under irradiation laser on and off every five seconds was recorded too.

\section{Cell Culture}

NIH3T3 cells (mouse embryonic fibroblast cell line, ATCC) were cultured in DMEM containing $10 \%$ fetal bovine serum, 100 units per $\mathrm{mL}$ penicillin and $100 \mu \mathrm{g} /$ $\mathrm{mL}$ streptomycin at $37^{\circ} \mathrm{C}$ under $5 \% \mathrm{CO}_{2}$. MDA-MB-231 cells (a human breast carcinoma cell line, ATCC) were cultured in MEM containing 10\% fetal bovine serum, 100 units per $\mathrm{mL}$ penicillin and $100 \mu \mathrm{g} / \mathrm{mL}$ streptomycin at $37^{\circ} \mathrm{C}$ under $5 \% \mathrm{CO}_{2}$.

\section{In vitro Cell Cytotoxicity}

In order to investigate the biosafety of TCPP-Iso NPs, NIH3T3 cells were added into a 96-well plate $\left(5 \times 10^{3}\right.$ cells/well) and cultured for $24 \mathrm{~h}$. After that, the TCPPIso NPs aqueous solution with different concentrations (equivalent concentrations of TCPP in TCPP-Iso NPs $10 \mu \mathrm{g} / \mathrm{mL}, \quad 30 \mu \mathrm{g} / \mathrm{mL}, \quad 50 \mu \mathrm{g} / \mathrm{mL}$, and $100 \mu \mathrm{g} / \mathrm{mL}$ ) were added into 96-well plate. $24 \mathrm{~h}$ later, cell viabilities were detected by CCK- 8 assay. At the same time, MDA-MB -231 cells were treated with different concentrations of ISO $(10 \mu \mathrm{g} / \mathrm{mL}, 30 \mu \mathrm{g} / \mathrm{mL}, 50 \mu \mathrm{g} / \mathrm{mL}$, and $100 \mu \mathrm{g} / \mathrm{mL})$. After incubation for $24 \mathrm{~h}$, cell viabilities were detected by CCK-8 assay.

\section{In vitro Photocytotoxicity}

The cultured MDA-MB-231 cells were added into a 96-well plate $\left(5 \times 10^{3}\right.$ cells $/$ well $)$ overnight. Then the cells were incubated with different concentrations of TCPP-NPs (equivalent TCPP concentration $10 \mu \mathrm{g} / \mathrm{mL}, 30 \mu \mathrm{g} / \mathrm{mL}, 50 \mu \mathrm{g} / \mathrm{mL}$ ) for $4 \mathrm{~h}$. Then the wells were irradiated with a $650 \mathrm{~nm}$ laser for 5 min at $6.5 \mathrm{~W} \cdot \mathrm{cm}^{-2}$. After incubation for another $20 \mathrm{~h}$, cell viabilities were tested by CCK-8 method. 


\section{In vitro Synergetic Effect of Chemotherapy and Photothermal}

\section{Therapy}

MDA-MB-231 cells were added into a 96-well plate $\left(5 \times 10^{3}\right.$ cells/well) overnight. The cells were incubated with PBS, Iso, TCPP-NPs, and TCPP-Iso NPs (equivalent TCPP concentration for TCPP-NPs and TCPP-Iso NPs $=30 \mu \mathrm{g} / \mathrm{mL}$, equivalent Iso concentration $=33.75 \mu \mathrm{g} / \mathrm{mL}$ ), respectively. After incubation for $4 \mathrm{~h}$, the cells in each well were irradiated by a $650 \mathrm{~nm}$ NIR laser at $6.5 \mathrm{~W} \cdot \mathrm{cm}^{-2}$ for $5 \mathrm{~min}$. After incubation for another $20 \mathrm{~h}$, cell viabilities were analyzed by CCK- 8 method.

For visualization of live or dead/late apoptotic cells, MDA-MB-231 cells were seeded in 96 -well plates $\left(5 \times 10^{3}\right.$ cells/well) and incubated overnight. Then, the original media were replaced by the fresh medium containing PBS, Iso, TCPP-NPs, or TCPP-Iso NPs (equivalent TCPP concentration for TCPP-NPs and TCPP-Iso NPs = $30 \mu \mathrm{g} / \mathrm{mL}$, equivalent Iso concentration $=33.75 \mu \mathrm{g} / \mathrm{mL}$ ), respectively, followed by irradiation for $5 \mathrm{~min}$ with 650 $\mathrm{nm}$ laser $\left(6.5 \mathrm{~W} \cdot \mathrm{cm}^{-2}\right)$ or not. After another 20 $\mathrm{h}$ incubation, Calcein-AM/PI kit was employed to stain the cells for visualization of the live or dead/late apoptotic cells. The fluorescence images were obtained by using a fluorescence microscope (IX 71, Olympus).

\section{Results and Discussion \\ Control of Combined-NPs' Size}

The TCPP-Iso combined NPs were prepared by the antisolvent precipitation process, as described in Figure 1. TCPP, Iso, and PEG- $b$-PLGA were primarily dissolved in DMF, and then transferred drop-wise into pure water with 9 times of volume under stirring. Then, the obtained suspensions were dialyzed for $24 \mathrm{~h}$ against Milli-Q water to obtain the NPs. For the development of drug-loaded NPs, control of NP size and size distribution is crucial. In the current work, the effect of ratio of polymer to drug was firstly investigated. Both the concentrations of TCPP and Iso were fixed at $0.5 \mathrm{mg} / \mathrm{mL}$, while the PEG- $b$-PLGA concentration was tuned from 1 to $5 \mathrm{mg} / \mathrm{mL}$. As shown in Figure $2 \mathrm{~A}$, the $\mathrm{R}_{\mathrm{h}}$ (Hydrodynamic radius) decreased from 108 to $87 \mathrm{~nm}$, and PDI deceased from 0.4 to 0.2 upon increasing polymer concentration from 1 to $1.5 \mathrm{mg} / \mathrm{mL}$. Further increasing polymer concentration led to decreased particle size to $75 \mathrm{~nm}$ without disturbing the narrow size distribution. The $\mathrm{R}_{\mathrm{h}}$ then increased to $107 \mathrm{~nm}$ with further increasing polymer concentration from 3 to $5 \mathrm{mg} / \mathrm{mL}^{38}$ The particle morphology was examined by static light scattering, and the angular independent diffusion coefficients of the NPs (Figure 2B) indicated the spherical shape
A

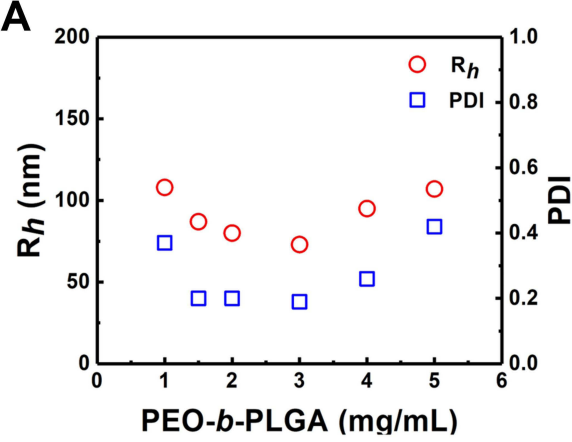

D

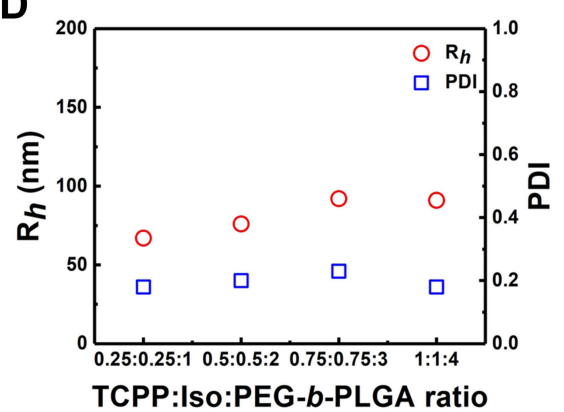

B

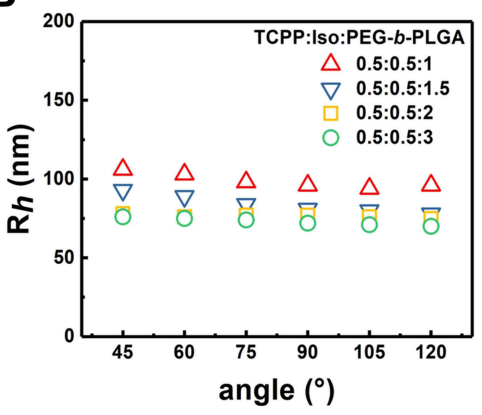

E

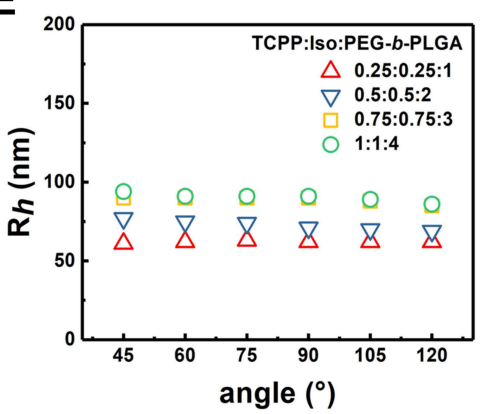

C

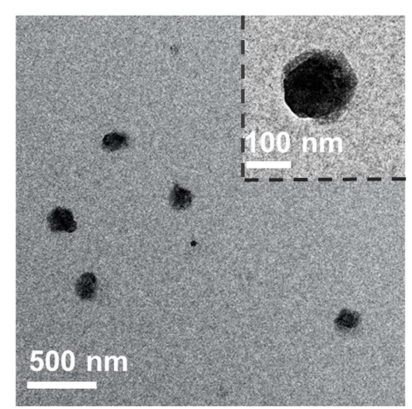

$\mathbf{F}$

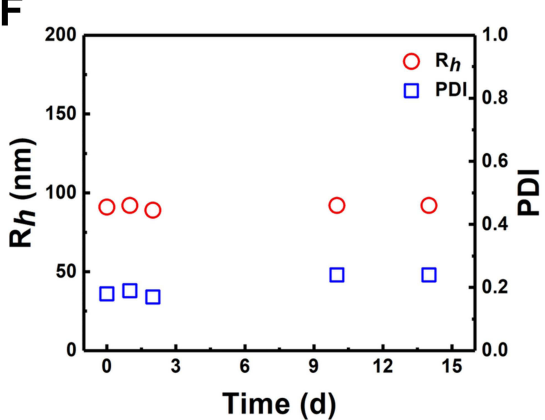

Figure 2 Hydrodynamic radius $\left(R_{h}\right)$ and size distribution (PDI) $(\mathbf{A})$, angular dependence of the diffusion coefficient $D(B)$, and TEM image (C) of NPs prepared at different TCPP-Iso/polymer ratio, concentrations of TCPP and Iso were fixed at $0.5 \mathrm{mg} / \mathrm{mL} ; R_{h}$ and PDI (D), and angular dependence of the diffusion coefficient D (E) of NPs prepared at different total concentrations of drug and polymers, the mass ratio of TCPP: Iso: PEG-b-PLGA was fixed at I: I: 4; (F) stability of combined NPs prepared at TCPP: Iso: PEG-b-PLGA = I: I: $4 \mathrm{mg} / \mathrm{mL}$. 
of the formed NPs. The morphology of combined NPs prepared at polymer concentration of $2 \mathrm{mg} / \mathrm{mL}$ was further confirmed by TEM (Figure 2C), and the estimated diameter of the NPs was around $170 \mathrm{~nm}$ on average, which is comparable to the light scattering results $\left(\mathrm{R}_{\mathrm{h}} \sim\right.$ $80 \mathrm{~nm})$.

Next, TCPP-Iso/polymer ratio was fixed at 1: 1: 4 , and the total concentration of drug and polymers varied from 0.25: $0.25: 1 \mathrm{mg} / \mathrm{mL}$ to $1: 1: 4 \mathrm{mg} / \mathrm{mL}$. As shown in Figure 2D, with the increasing total concentration, the Rh slightly grew from $65 \mathrm{~nm}$ to $95 \mathrm{~nm}$ with a constant PDI around 0.2. The combined NPs were spherical in shape, evidenced by angular independent diffusion coefficients (Figure 2E). The UV-Vis and FT-IR spectrum were further measured to confirm the encapsulation of TCPP and Iso inside the NPs (Figure S2). The encapsulation of TCPP was certified by the absorbance at $521 \mathrm{~nm}$ in UV-Vis spectrum, and the wavelength of $960 \mathrm{~cm}^{-1}$ and $3050 \mathrm{~cm}^{-1}$ in FT-IR spectrum; ${ }^{39,40}$ the encapsulation of Iso was certified by the absorbance at $290 \mathrm{~nm}$ in UV-Vis spectrum, and the wavelength of $1250 \mathrm{~cm}^{-1}$ in FT-IR spectrum. $^{41,42}$ Moreover, the combined NPs exhibited good stability over time, both the particle size and PDI hardly changed within 15 days (Figure 2F, Table S1), with encapsulation efficiencies of $18 \%$ for Iso and $16 \%$ for TCPP. $^{43}$

For the construction of drug-loaded NPs, controlled release is an important property. Here, the release behavior of TCPP-Iso combined NPs prepared at ratio of TCPP: Iso: PEG- $b$-PLGA $=1: 1: 4$ and NPs concentration of $4.34 \mathrm{mg} / \mathrm{mL}$ was measured in PBS solution at $\mathrm{pH} 7.4$ and $37^{\circ} \mathrm{C}$. Figure 3 shows that the TCPP and Iso displayed similar release behavior, that is, 58\% of TCPP and $42 \%$ Iso were released during the first $12 \mathrm{~h}$, followed by a slow release. The current results demonstrated the successful encapsulation and feasibility for controlled release of the drug.

\section{Photothermal Conversion}

Figure 4A and S3a show the temperature evolution curves of deionized water in the presence of TCPP-Iso combined NPs with different TCPP concentrations and TCPP NPs respectively under $650 \mathrm{~nm}$ laser irradiation. By increasing the concentration of TCPP, the temperature of the solution increased obviously, especially at $30 \mu \mathrm{g} / \mathrm{mL}$; it increased from about 26.0 to $42.0^{\circ} \mathrm{C}$, while the temperature of deionized water only increased by $1.5^{\circ} \mathrm{C}$. It has been reported that raised temperature between 40 and $42^{\circ} \mathrm{C}$ is the

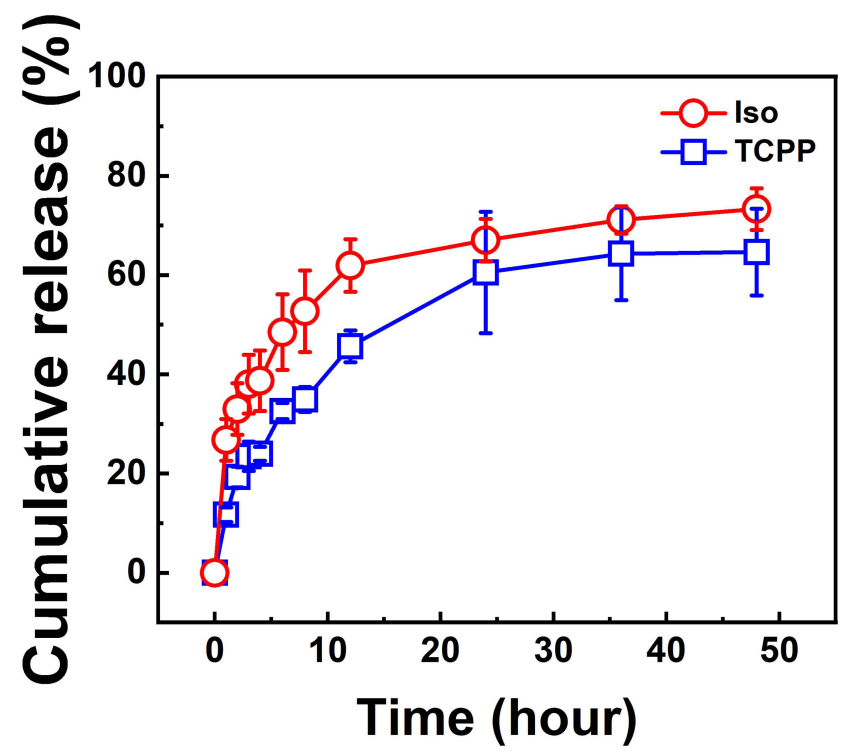

Figure 3 Cumulative release of TCPP and Iso of the TCPP-lso combined NPs, in PBS buffer $\left(\mathrm{pH} \mathrm{7.4)}\right.$ and $37^{\circ} \mathrm{C}$. NPs were prepared at concentration of TCPP: Iso: PEG-b-PLGA = I: I: $4 \mathrm{mg} / \mathrm{mL}$.

preferred temperature range, which could not only help to enhance drug-loaded NPs' extravasation from tumor blood vessels but also help to protect the surrounding normal tissue from additional heat damage. ${ }^{13}$ Furthermore, to validate the photothermal stability of the TCPP-Iso combined NPs and TCPP NPs' ability to respond to the photoexcitation, three cycles of laser on/ off with a $650 \mathrm{~nm}$ laser were recorded (Figure 4B and $\underline{\mathrm{S} 3 \mathrm{~b}}$. Consistent temperature elevation was observed, indicating high photothermal stability.

\section{In vitro Synergetic Effect of Photothermal and Chemotherapy}

The synergetic effect of photothermal and chemotherapy was systematically examined in vitro, as shown in Figure 5. The commonly used mouse embryonic fibroblast (NIH 3T3) cell line was chosen as the model normal tissue cell line, while human breast cancer (MDA-MB-231) cell line was chosen as the model cancer cell line. The TCPPIso combined NPs did not show apparent toxicity to normal tissue cell line (Figure 5A), from $10 \mu \mathrm{g} / \mathrm{mL}$ to $100 \mu \mathrm{g} /$ $\mathrm{mL}$ (concentration of TCPP). This finding indicated that the combined NPs are suitable for biomedical applications due to good biocompatibility.

For cancer cells, the Iso exhibited inhibition effect on MDA-MB-231 cell lines depending on Iso concentration, as shown in Figure 5B; about $80 \%$ cancer cells stayed alive at concentration of $30 \mu \mathrm{g} / \mathrm{mL}, 66 \%$ cancer cells 
A

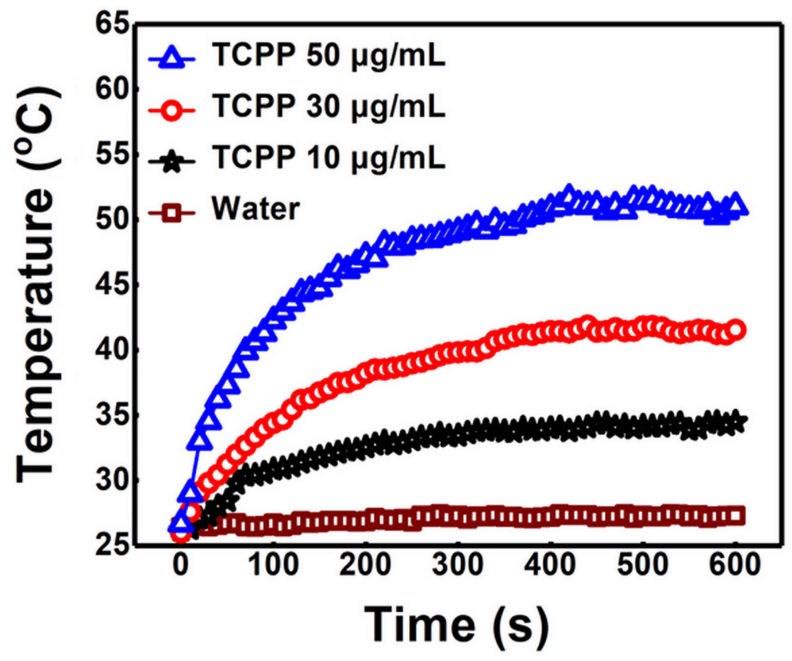

B

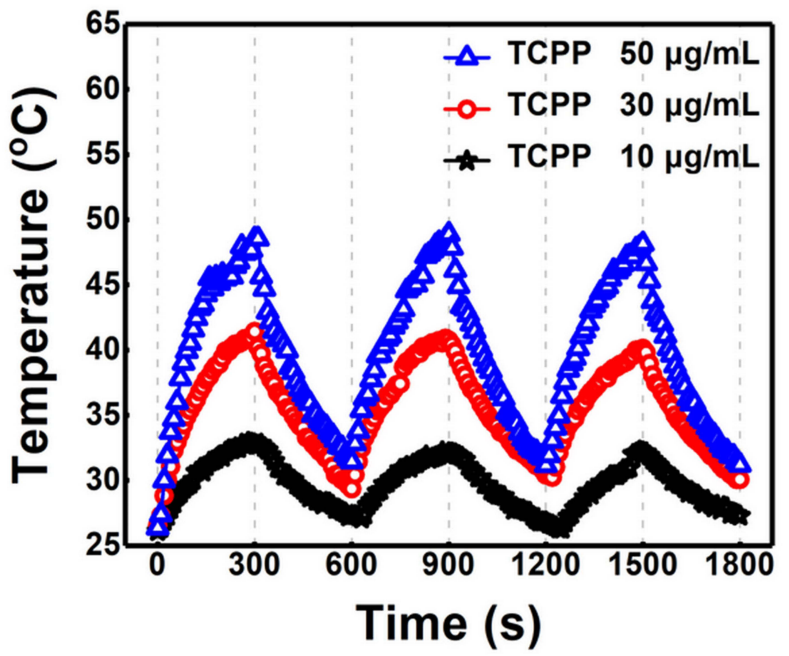

Figure 4 (A) Temperature evolution of TCPP-Iso combined NPs under $650 \mathrm{~nm}$ laser irradiation $\left(6.5 \mathrm{~W} \cdot \mathrm{cm}^{-2}\right)$ at different TCPP concentrations; (B) temperature evolution of NPs solution with 3 cycles of laser on/off under $650 \mathrm{~nm}$ laser irradiation $\left(6.5 \mathrm{~W} \cdot \mathrm{cm}^{-2}\right)$ at different TCPP concentrations. NPs were prepared at TCPP: Iso: PEG-b-PLGA = I: I: $4 \mathrm{mg} / \mathrm{mL}$, and diluted to different TCPP concentrations.

were alive at concentration of $50 \mu \mathrm{g} / \mathrm{mL}$, while only $25 \%$ cancer cells were alive at concentration of $100 \mu \mathrm{g} / \mathrm{mL}$. Figure 5C shows the TCPP alone did not cause harm to cancer cells without the laser irradiation, while with the laser irradiation there were still $46 \%$ cancer cells alive at TCPP concentration of $30 \mu \mathrm{g} / \mathrm{mL}$. Interestingly, as shown in Figure 5D, the viability of cancer cells obviously decreased to only $9 \%$ with TCPP-Iso combined NPs at $30 \mu \mathrm{g} / \mathrm{mL}$ under Laser irradiation. In contrast, neither TCPP NPs with laser irradiation nor Iso alone showed effective cell-killing at the corresponding agent concentration, indicated by the $44 \%$ viability of cancer cells for TCPP-NPs under laser irradiation and $76 \%$ viability for Iso respectively. Meanwhile, the Calcein-AM/PI method was used to visually measure the synergistic cytotoxic potency, in which the live cells showed green fluorescence and dead or late apoptotic cells showed red fluorescence (Figure 5E).

Cells in $\mathrm{PBS}+\mathrm{L}$ group (treated with $\mathrm{PBS}$ and laser irradiation) and TCPP NPs group showed green fluorescence in most horizon, indicating that the negligible cell death was induced by laser irradiation alone or TCPP NPs themselves. While the groups of TCPP+L (TCPP NPs with laser irradiation), TCPP-Iso NPs, and Iso induced a moderate level of cell death (partial red fluorescence). Furthermore, intensive red fluorescence showed up in TCPP-Iso NPs+L group (TCPP-Iso NPs with laser irradiation). Therefore, the efficient cancer cell killing ability of TCPP-Iso combined NPs with laser irradiation confirms the synergistic effect of photo-chemotherapy, acquiring efficient inhibition of cancer cells at a relatively mild temperature.

\section{Conclusion}

Tetra(4-carboxyphenyl) porphine (TCPP) and isoliensinine (Iso) have been successfully encapsulated in PEG$b$-PLGA polymeric nanoparticles by means of precipitation. The design construct well-defined TCPP-Iso combined NPs with a high stability over time. Specifically, tuning TCPP-Iso/polymer ratio led to radius changing from 110 to $75 \mathrm{~nm}$ with narrow size distribution, while tuning total concentration of drug and polymers led to radius varying from $65 \mathrm{~nm}$ to $95 \mathrm{~nm}$ with narrow size distribution. The combined NPs exhibited a consequently cumulative release of TCPP and of Iso within 24h. Besides, the NPs displayed increased temperature variation curves with the increasing concentration, and combined NPs at $30 \mu \mathrm{g} / \mathrm{mL}$ TCPP concentration showed the preferred temperature range between 42 and $43^{\circ} \mathrm{C}$. Moreover, the efficient synergistic effect of TCPP-Iso combined NPs was observed for the killing of cancer cells at a relatively mild temperature rising under laser irradiation, while the NPs did not show apparent toxicity to normal tissue cell line. Our study confirms that the combination of TCPP and Iso could achieve a synergistic effect for killing cancer cells, and the revealed findings shall be helpful for the design and preparation of functional PTT agents. 
A

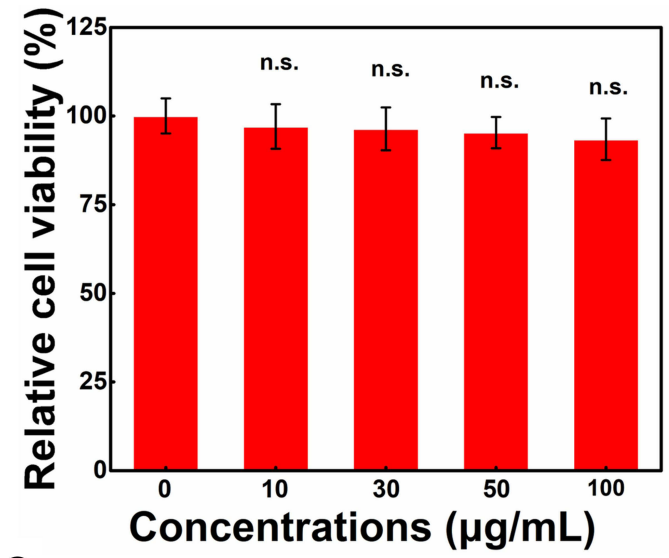

C

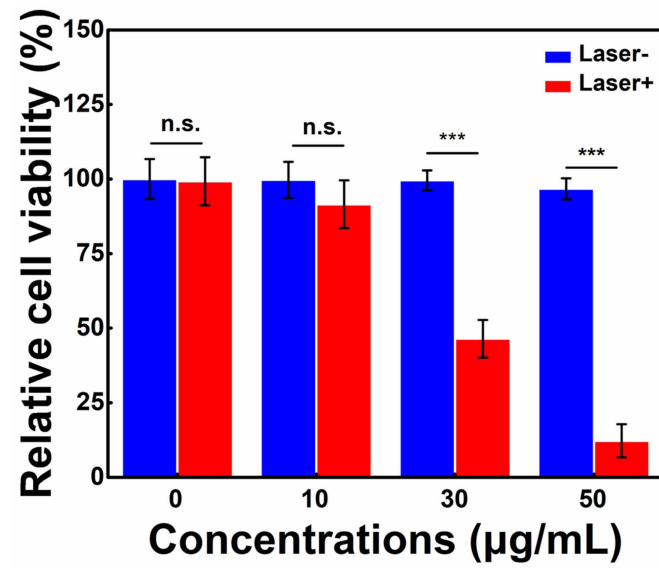

B

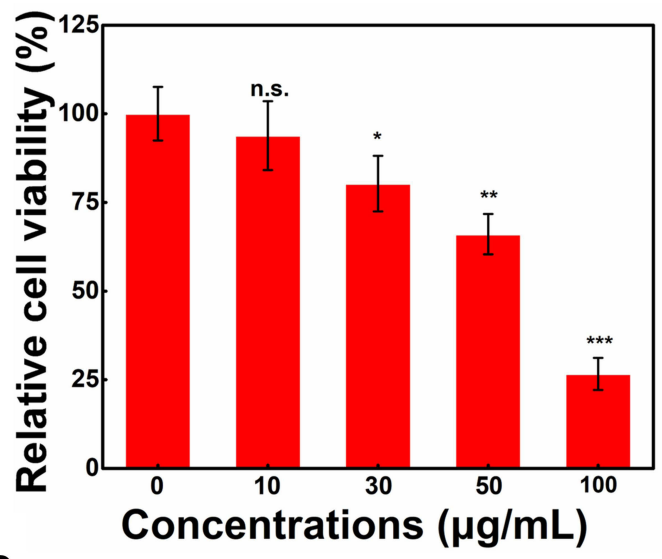

D

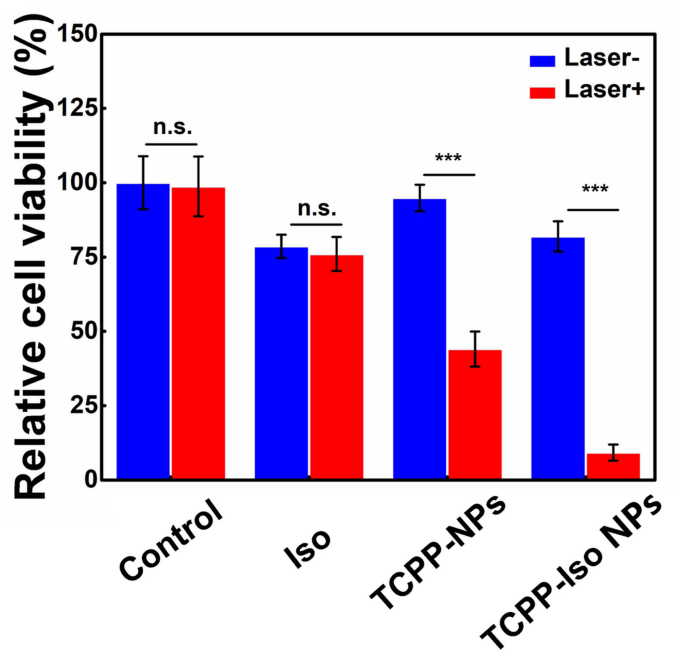

E

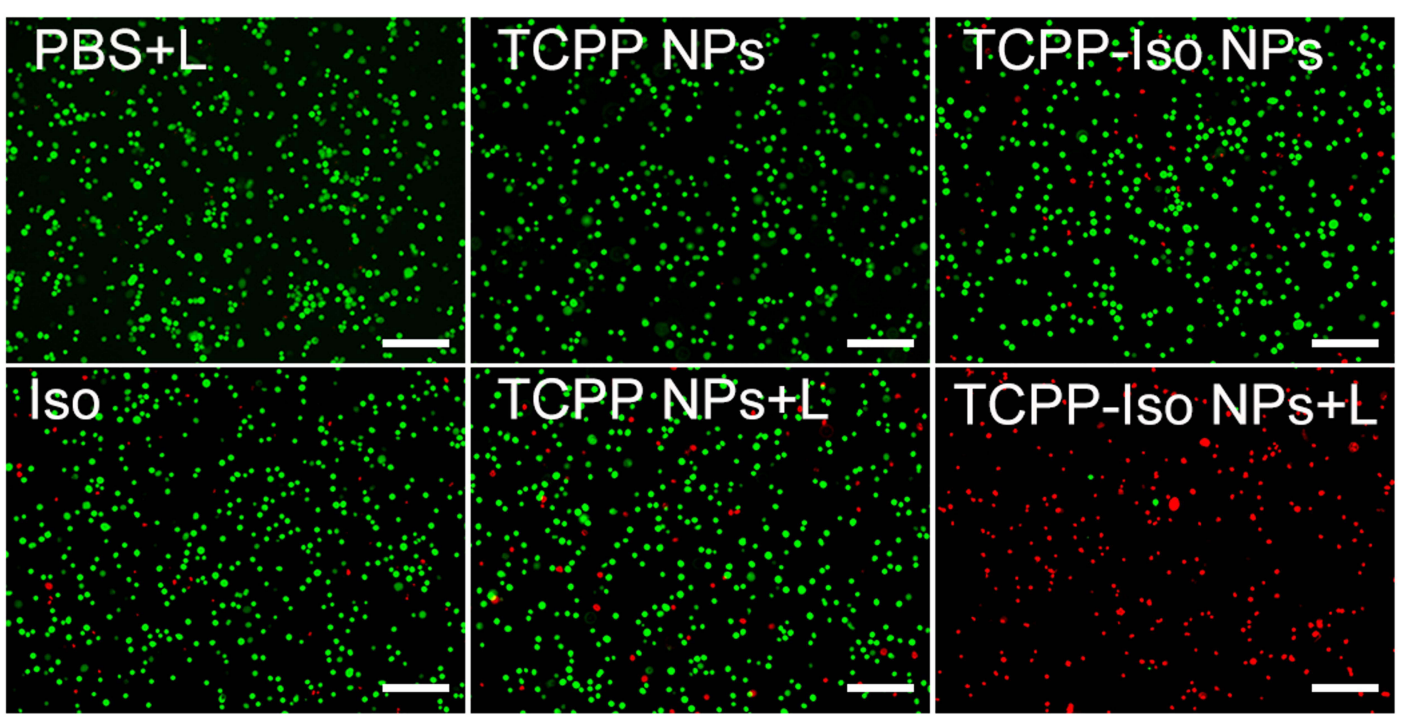

Figure 5 (A) Cell viability of TCPP-Iso combined NPs prepared at different TCPP concentrations in NIH $3 T 3$ normal cell line; (B) cell viability of Iso at different concentrations in MDA-MB-23I cancer cell line; (C) cytotoxicity of TCPP-NPs with laser irradiation at different TCPP concentrations in MDA-MB-23I cell line (650 nm, 6.5 $\left.W \cdot \mathrm{cm}^{-2}, 5 \mathrm{~min}\right)$; (D) cytotoxicity of PBS, Iso, TCPP-NPs, and TCPP-Iso combined NPs with or without laser irradiation in MDA-MB-23I cell line $\left(650 \mathrm{~nm}, 6.5 \mathrm{~W} \cdot \mathrm{cm}{ }^{-2}, 5\right.$ $\mathrm{min})$; (E) fluorescent images of MDA-MB-23I cells treated with PBS+Laser, TCPP NPs, TCPP NPs+Laser, Iso, TCPP-Iso NPs, and TCPP-Iso NPs+Laser. After the staining by Calcein-AM and PI (650 nm, $\left.6.5 \mathrm{~W} \cdot \mathrm{cm}^{-2}, 5 \mathrm{~min}\right) .{ }^{*} \mathrm{p}<0.05,{ }^{*}{ }_{\mathrm{p}}<0.01$, *** $<<0.00 \mathrm{I}$. Scale bar: $200 \mu \mathrm{m}$. 


\section{Acknowledgments}

This research was funded by the National Natural Science Foundation of China (NSFC) for Young Scholars (21706074), “1000 Foreign Experts Program" (WQ20163100341), and Funda-mental Research Funds for the Central Universities (222201814007).

\section{Disclosure}

The authors report no conflicts of interest in this work.

\section{References}

1. Bray F, Ferlay J, Soerjomataram I, et al. Global cancer statistics 2018: GLOBOCAN estimates of incidence and mortality worldwide for 36 cancers in 185 countries. CA Cancer J Clin. 2018;68 (6):394-424. doi:10.3322/caac.21492.

2. DeSantis CE, Ma J, Gaudet MM, et al. Breast cancer statistics, 2019. CA Cancer J Clin. 2019;69(6):438-451. doi:10.3322/caac.21583.

3. Harbeck N, Penault-Llorca F, Cortes J, et al. Breast cancer. Nat Rev Dis Primers. 2019;5(1):66. doi:10.1038/s41572-019-0111-2.

4. Siegel RL, Miller KD, Jemal A. Cancer statistics, 2020. CA Cancer $J$ Clin. 2020;70(1):7-30. doi:10.3322/caac.21590.

5. Yang $\mathrm{P}$, Zhang $\mathrm{S}$, Zhang N, et al. Tailoring synthetic melanin nanoparticles for enhanced photothermal therapy. ACS Appl Mater Interfaces. 2019;11(45):42671-42679. doi:10.1021/acsami.9b16861

6. Zou Y, Zhao J, Zhu J, et al. A mussel-inspired polydopamine-filled cellulose aerogel for solar-enabled water remediation. ACS Appl Mater Interfaces. 2021;13(6):7617-7624. doi:10.1021/ acsami.0c22584

7. Abadeer NS, Murphy CJ. Recent progress in cancer thermal therapy using gold nanoparticles. J Phys Chem C. 2016;120(9):4691-4716. doi:10.1021/acs.jpcc.5b11232.

8. Cherukula K, Manickavasagam Lekshmi K, Uthaman S, et al. Multifunctional inorganic nanoparticles: recent progress in thermal therapy and imaging. Nanomaterials (Basel). 2016;6(4):76. doi:10.3390/nano6040076

9. Gai SL, Yang GX, Yang PP, et al. Recent advances in functional nanomaterials for light-triggered cancer therapy. Review. Nano Today. 2018;19:146-187. doi:10.1016/j.nantod.2018.02.010

10. Hussein EA, Zagho MM, Nasrallah GK, Elzatahry AA. Recent advances in functional nanostructures as cancer photothermal therapy. Int $J$ Nanomedicine. 2018;13:2897-2906. doi:10.2147/IJN. S161031

11. Zou Y, Chen X, Yang P, et al. Regulating the absorption spectrum of polydopamine. Sci Adv. 2020;6(36):bb4696. doi:10.1126/sciadv abb4696

12. Deng X, Shao Z, Zhao Y. Solutions to the drawbacks of photothermal and photodynamic cancer therapy. Adv Sci (Weinh). 2021;8 (3):2002504. doi:10.1002/advs.202002504

13. Liu Y, Bhattarai P, Dai Z, Chen X. Photothermal therapy and photoacoustic imaging via nanotheranostics in fighting cancer. Chem Soc Rev. 2019;48(7):2053-2108. doi:10.1039/c8cs00618k

14. Gao G, Jiang YW, Guo Y, et al. Enzyme-mediated tumor starvation and phototherapy enhance mild-temperature photothermal therapy. Adv Funct Mater. 2020;30:16. doi:10.1002/adfm.201909391

15. Gao G, Jiang YW, Sun W, et al. Molecular targeting-mediated mild-temperature photothermal therapy with a smart albumin-based nanodrug. Small. 2019;15(33):e1900501. doi:10.1002/ smll.201900501

16. Yang Y, Zhu W, Dong Z, et al. 1D coordination polymer nanofibers for low-temperature photothermal therapy. Adv Mater. 2017;29(40). doi:10.1002/adma.201703588
17. Wang Y, Huang Q, He X, et al. Multifunctional melanin-like nanoparticles for bone-targeted chemo-photothermal therapy of malignant bone tumors and osteolysis. Biomaterials. 2018;183:10-19. doi:10.1016/j.biomaterials.2018.08.033

18. Gao S, Zhou H, Cui S, Shen H. Bottom-up synthesis of MoS2 nanospheres for photothermal treatment of tumors. Photochem Photobiol Sci. 2018;17(10):1337-1345. doi:10.1039/c8pp00198g

19. Jia X, Xu W, Ye Z, et al. Functionalized graphene@gold nanostar/ lipid for pancreatic cancer gene and photothermal synergistic therapy under photoacoustic/photothermal imaging dual-modal guidance. Small. 2020;16(39):e2003707. doi:10.1002/smll.202003707

20. Pierini F, Nakielski P, Urbanek O, et al. Polymer-based nanomaterials for photothermal therapy: from light-responsive to multifunctional nanoplatforms for synergistically combined technologies. Biomacromolecules. 2018;19(11):4147-4167. doi:10.1021/acs. biomac. $8 \mathrm{~b} 01138$

21. Rastinehad AR, Anastos H, Wajswol E, et al. Gold nanoshell-localized photothermal ablation of prostate tumors in a clinical pilot device study. Proc Natl Acad Sci USA. 2019;116 (37):18590-18596. doi:10.1073/pnas.1906929116

22. Yao MQ, Ma YC, Liu H, et al. Enzyme degradable hyperbranched polyphosphoester micellar nanomedicines for NIR imaging-guided chemo-photothermal therapy of drug-resistant cancers. article. Biomacromolecules. 2018;19(4):1130-1141. doi:10.1021/acs. biomac.7b01793

23. Liu S, Liu Y, Hu C, Zhao X, Ma P, Pang M. Boosting the antitumor efficacy over a nanoscale porphyrin-based covalent organic polymer via synergistic photodynamic and photothermal therapy. Chem Commun (Camb). 2019;55(44):6269-6272. doi:10.1039/c9cc02345c

24. Wang D, Zhang Z, Lin L, et al. Porphyrin-based covalent organic framework nanoparticles for photoacoustic imaging-guided photodynamic and photothermal combination cancer therapy. Biomaterials. 2019;223:119459. doi:10.1016/j.biomaterials.2019.119459

25. Wu F, Chen L, Yue L, et al. Small-molecule porphyrin-based organic nanoparticles with remarkable photothermal conversion efficiency for in vivo photoacoustic imaging and photothermal therapy. ACS Appl Mater Interfaces. 2019;11(24):21408-21416. doi:10.1021/ acsami.9b06866

26. Yan D, Liu X, Deng G, et al. Facile assembling of novel polypyrrole nanocomposites theranostic agent for magnetic resonance and computed tomography imaging guided efficient photothermal ablation of tumors. J Colloid Interface Sci. 2018;530:547-555. doi:10.1016/j. jcis.2018.07.001

27. Zeng JY, Zhang MK, Peng MY, Gong D, Zhang XZ. Porphyrinic metal-organic frameworks coated gold nanorods as a versatile nanoplatform for combined photodynamic/photothermal/chemotherapy of tumor. Adv Funct Mater. 2018;28(8):1705451. doi:10.1002/ adfm. 201705451

28. Zhang C, Pan H, Wang X, Sun SK. Microwave-assisted ultrafast fabrication of high-performance polypyrrole nanoparticles for photothermal therapy of tumors in vivo. Biomater Sci. 2018;6 (10):2750-2756. doi:10.1039/c8bm00653a

29. Zhang H, Tian XT, Shang Y, Li YH, Yin XB. Theranostic Mn-Porphyrin metal-organic frameworks for magnetic resonance imaging-guided nitric oxide and photothermal synergistic therapy. ACS Appl Mater Interfaces. 2018;10(34):28390-28398. doi:10.1021/acsami.8b09680

30. Zhang S, Lv H, Zhao J, Cheng M, Sun S. Synthesis of porphyrin-conjugated silica-coated $\mathrm{Au}$ nanorods for synergistic photothermal therapy and photodynamic therapy of tumor. Nanotechnology. 2019;30(26):265102. doi:10.1088/1361-6528/ ab0bd1

31. Zou Q, Abbas M, Zhao L, Li S, Shen G, Yan X. Biological photothermal nanodots based on self-assembly of peptide-porphyrin conjugates for antitumor therapy. $J$ Am Chem Soc. 2017;139 (5):1921-1927. doi:10.1021/jacs.6b11382 
32. Kang EJ, Lee SK, Park KK, Son SH, Kim KR, Chung WY. Liensinine and nuciferine, bioactive components of Nelumbonucifera, inhibit the growth of breast cancer cells and breast cancer-associated bone loss. Evid Based Complement Alternat Med. 2017;2017:1583185. doi:10.1155/2017/1583185

33. Manogaran P, Beeraka NM, Huang CY, Vijaya Padma V. Neferine and isoliensinine enhance 'intracellular uptake of cisplatin' and induce 'ROS-mediated apoptosis' in colorectal cancer cells A comparative study. Food Chem Toxicol. 2019;132:110652. doi:10.1016/j.fct.2019.110652

34. Tian Y, Qian S, Jiang Y, et al. The interaction between human breast cancer resistance protein (BCRP) and five bisbenzylisoquinoline alkaloids. Int $J$ Pharm. 2013;453(2):371-379. doi:10.1016/j. ijpharm.2013.05.053

35. Wang Y, Li YJ, Huang XH, et al. Liensinine perchlorate inhibits colorectal cancer tumorigenesis by inducing mitochondrial dysfunction and apoptosis. Food Funct. 2018;9(11):5536-5546. doi:10.1039/ c8fo01137k

36. Zhang $\mathrm{X}$, Wang $\mathrm{X}$, Wu T, et al. Isoliensinine induces apoptosis in triple-negative human breast cancer cells through ROS generation and p38 MAPK/JNK activation. Sci Rep. 2015;5:12579. doi:10.1038/ srep 12579

37. Zhou J, Li G, Zheng Y, et al. A novel autophagy/mitophagy inhibitor liensinine sensitizes breast cancer cells to chemotherapy through DNM1L-mediated mitochondrial fission. Autophagy. 2015;11 (8):1259-1279. doi:10.1080/15548627.2015.1056970
38. Li G, Meng S, Feng Y. Encapsulation of modified pigment yellow 110 (PY110) for electrophoretic display. J Mater Res. 2016;31 (15):2261-2267. doi:10.1557/jmr.2016.244

39. Wang C, Cao F, Ruan Y, et al. Specific generation of singlet oxygen through the russell mechanism in hypoxic tumors and GSH depletion by $\mathrm{Cu}$-TCPP nanosheets for cancer therapy. Angew Chem Int Ed Engl. 2019;58(29):9846-9850. doi:10.1002/anie.201903981

40. Zhao Y, Wang J, Pei R. Micron-sized ultrathin metal-organic framework sheet. J Am Chem Soc. 2020;142(23):10331-10336. doi: $10.1021 /$ jacs.0c04442

41. Itoh A, Saitoh T, Tani K, et al. Bisbenzylisoquinoline alkaloids from Nelumbo nucifera. Chem Pharm Bull(Tokyo). 2011;59(8):947-951. doi:10.1248/cpb.59.947

42. Shu G, Yue L, Zhao W, et al. Isoliensinine, a bioactive alkaloid derived from embryos of Nelumbo nucifera, induces hepatocellular carcinoma cell apoptosis through suppression of NF-kappaB Signaling. $J$ Agric Food Chem. 2015;63(40):8793-8803. doi:10.1021/acs.jafc.5b02993

43. Kong L, Chen R, Wang X, et al. Controlled co-precipitation of biocompatible colorant-loaded nanoparticles by microfluidics for natural color drinks. Lab Chip. 2019;19(12):2089-2095. doi:10.1039/ c9lc00240e
International Journal of Nanomedicine

\section{Publish your work in this journal}

The International Journal of Nanomedicine is an international, peerreviewed journal focusing on the application of nanotechnology in diagnostics, therapeutics, and drug delivery systems throughout the biomedical field. This journal is indexed on PubMed Central, MedLine, CAS, SciSearch ${ }^{\mathbb{R}}$, Current Contents ${ }^{\mathbb{R}} /$ Clinical Medicine, $^{-}$

\section{Dovepress}

Journal Citation Reports/Science Edition, EMBase, Scopus and the Elsevier Bibliographic databases. The manuscript management system is completely online and includes a very quick and fair peer-review system, which is all easy to use. Visit http://www.dovepress.com/ testimonials.php to read real quotes from published authors. 